\title{
Fédération de Russie
}

\section{Elena Serebryakova}

\section{(2) OpenEdition}

\section{Journals}

Édition électronique

URL : https://journals.openedition.org/rdctss/2053

DOI : $10.4000 /$ rdctss.2053

ISSN : 2262-9815

Éditeur

Centre de droit comparé du travail et de la sécurité sociale

Édition imprimée

Date de publication : 1 avril 2018

Pagination : 156-159

ISSN : 2117-4350

\section{Référence électronique}

Elena Serebryakova, «Fédération de Russie », Revue de droit comparé du travail et de la sécurité sociale [En ligne], 1 | 2018, mis en ligne le 01 novembre 2021, consulté le 12 novembre 2021. URL : http:// journals.openedition.org/rdctss/2053; DOI : https://doi.org/10.4000/rdctss.2053

\section{(c) $(1)(9)$}

Revue de droit comparé du travail et de la sécurité sociale est mise à disposition selon les termes de la Licence Creative Commons Attribution - Pas d'Utilisation Commerciale - Pas de Modification 4.0 International. 


\title{
ELENA SEREBRYAKOVA
}

\author{
Université d’Etat de technologie de Moscou N.E. Bauman
}

\section{I - LES SALAIRES}

Il convient tout d'abord de noter que le projet de loi sur l'augmentation du salaire mensuel minimum a été adopté et est entré en vigueur le $1^{\text {er }}$ janvier 20181. Ce projet, présenté au $2^{\text {ème }}$ semestre ${ }^{2}$, a été voté sans modification des montants. Actuellement, le salaire mensuel minimum est fixé à 9489 roubles, ce qui représente $85 \%$ du minimum vital de la population active durant le deuxième trimestre de 2017. Selon la loi, à partir de 2019, le salaire minimum sera ajusté sur le minimum vital du deuxième trimestre de l'année précédente. À partir du $1^{\text {er }}$ janvier 2018, ce montant est fixé par le ministère du travail et de la protection sociale en coordination avec le ministère du développement économique et le ministère des finances ${ }^{3}$. Par ailleurs, un autre projet, $n^{\circ} 374313-7$, a été déposé devant la Douma d'État qui prévoit que le salaire minimum atteindra le minimum vital (11 163 roubles) le $1^{\text {er }}$ mai 2018.

La loi du 5 février $2018^{4}$ a modifié l'article 131 du Code du travail, qui déterminait la règle du paiement du salaire uniquement en roubles. Elle met un terme à l'incohérence entre cet article et les dispositions de la Loi sur la réglementation des devises et le contrôle des changes ${ }^{5}$. Cette dernière autorise les entreprises russes à verser le salaire en devises étrangères au salarié étranger. Des dispositions régissent la perception par le salarié russe travaillant pour une société russe en dehors du territoire de la Russie de son salaire en devises étrangères. Par exemple, une entreprise russe a le droit de verser le salaire dans une autre devise que le rouble si le salarié russe travaille dans un bureau de représentation situé à l'étranger, qui n'est pas une filiale.

1 Фелеральный закон от 28.12.2017 n421-Ф3 «О внесении изменений в отлельные законодательные акты Российской Федерации в части повышения минимального размера оплаты труда до прожиточного минимума трудоспособного населения ». http://publication.pravo.gov.ru/Document/View/0001201712290015

2 Voir A. Alexandrova. "Le salaire minimum, " Revue de Droit Comparé du travail et de la Sécurité Sociale, n²017/3, p. 196-199.

3 П. 1 Постановления Правительства РФ от 30.12.2017 n¹702 «О порядке установления величины прожиточного минимума на душу населения и по основным социальноАемографическим группам населения в целом по Российской Федерации ». http://publication.pravo.gov.ru/Document/View/0001201712310055

4 Федеральный закон от 05.02.2018 n8-Ф3 «О внесении изменения в статью 131 Трудового кодекса Российской Федерации ».

http://publication.pravo.gov.ru/Document/View/0001201802050024

5 Федеральный закон от 10.12.2003 № 173-Ф3 «О валютном регулировании и валютном контроле » 


\section{II - LES ALLOCATIONS FAMILIALES}

La situation démographique en Russie qui s'est dégradée fortement après la chute de I'URSS, a commencé à se stabiliser légèrement en 2013; cependant le taux de natalité restait en dessous du niveau de l'année 1990 (1,9 enfants par femme). Actuellement, il rechute $(1,6$ enfants en janvier - novembre 2017) 6 . La Russie a perdu 122000 habitants de janvier à octobre 2017, alors qu'à la même période en 2016, la population du pays a augmenté de 18600 habitants $^{7}$. La baisse naturelle de la population est compensée par l'immigration. La dernière mesure importante pour soutenir la démographie a été I'instauration en 2007 du « capital maternel », par la Loi sur les mesures supplémentaires de soutien de l'État aux familles avec enfants ${ }^{8}$. Le capital maternel est une allocation spécifique financée par le budget fédéral. Fixé pour 2007 à 250000 roubles (environ 7143 euros), ce montant a été réévalué chaque année jusqu'en 2015 en fonction de l'inflation. Il a été gelé à 453026 roubles (environ 6500 euros) en avril 2015.

Pour devenir allocataire, il n'est pas nécessaire d'être affilié au régime obligatoire de sécurité sociale. Ce sont uniquement, les citoyens russes qui ont le droit à l'aide sociale sous la forme du capital maternel qui n'est versé qu'une seule fois: les mères (ou les pères seuls), de deux enfants ou plus, y compris adoptés, dont au moins l'un est né (ou adopté) à partir $1^{\mathrm{er}}$ janvier 2007. Ces personnes disposent du capital maternel sur la base d'un certificat spécial délivré par le Fond de pension. En règle générale, jusqu'en 2018, ils ne pouvaient l'utiliser, intégralement ou partiellement, qu'à l'expiration d'un délai de trois ans à partir de la naissance (ou adoption) du deuxième, ou des enfants nés ultérieurement, et uniquement aux fins d'amélioration des conditions de vie, d'éducation des enfants, de constitution d'une épargne retraite (pour les femmes), de financement d'achats de matériel et/ou de services destinés à faciliter l'intégration sociale des enfants handicapés. Ce capital maternel ne pouvait pas être versé en espèces.

Les résultats de cette mesure ne sont pas évidents. Elle n'a pas provoqué de babyboom en 2007, ni plus tard. Pour autant, la simple analyse de données statistiques montre que le taux de natalité, très bas sur la période 1995-2006, a augmenté significativement jusqu'à 2017, quand le gouvernement a annoncé de nouvelles mesures pour soutenir les familles avec des enfants. Initialement, le programme de capital maternel avait été lancé pour 10 ans. En 2015, son terme a été prolongé jusqu'à 31 décembre 2018.

La loi n 432-Ф3 du 28 décembre $2017^{9}$ a établi que le capital maternel peut être attribué aux parents si le deuxième enfant ou suivant est né avant le 31 décembre 2021. Le programme ne s'achèvera donc pas en 2018. Selon cette loi, le capital maternel peut être versé en espèces mensuellement aux allocataires russes qui résident en Russie à

6 Les informations sur la situation démographique en Russie sont disponibles sur le site de l'agence des statistiques Rosstat

http://www.gks.ru/wps/wcm/connect/rosstat main/rosstat/ru/statistics/population/demography/\#

7 Voir les informations sur la situation socio-économique en Russie en 2017 publié par l'agence des statistiques Rosstat, p. 117. http://www.gks.ru/free doc/doc 2017/info/oper-12-2017.pdf

8 Федеральный закон от 29.12.2006 n² 256-Ф3 «О Аополнительных мерах государственной подАержки семей, имеющих детей "

9 Федеральный закон от 28.12.2017 n432-Ф3 «О внесении изменений в Федеральный закон «О дополнительных мерах государственной поддержки семей, имеющих детей ».

http://publication.pravo.gov.ru/Document/View/0001201712290001 
condition que le quotient familial ne dépasse pas 1,5 fois le minimum vital de la population active. Le versement mensuel correspond au minimum vital des enfants. II est entendu que l'expression «minimum vital» désigne le montant établi au niveau régional pour le deuxième trimestre de l'année précédant l'année de la demande d'allocation. Cette nouvelle mesure est accessible aux parents ayant le deuxième enfant ou le suivant né ou

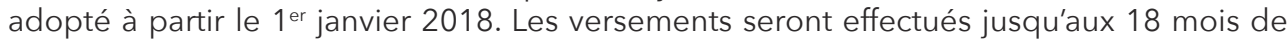
l'enfant.

Une autre modification importante vise les cas exceptionnels d'utilisation du capital maternel avant le troisième anniversaire de l'enfant. La liste des situations justifiant cette utilisation exceptionnelle a été élargie. Dorénavant, les allocataires peuvent utiliser le capital maternel à partir de la naissance (ou adoption) du deuxième enfant ou du suivant non seulement pour payer les frais de garantie pour l'achat d'un logement, rembourser le prêt immobilier et acheter du matériel destiné à faciliter l'intégration sociale des enfants handicapés, mais également pour couvrir les frais de garde en crèche ou en école maternelle et pour recevoir le versement mensuel mentionné ci-dessus. Dès 2013, les allocations mensuelles pour toute naissance ou adoption à partir du troisième enfant ont été mises en œuvre dans les régions aux situations démographiques les plus inquiétantes. En 2017, cette prestation existait dans 67 régions sur 85, dont 50 recevaient les dotations budgétaires fédérales. En 2018, leur nombre passera de 50 à 60 .

Une nouvelle allocation mensuelle financée par le budget fédéral, en vertu de la loi $n^{\circ}$ 418-Ф3 du 28 décembre 201710, est entrée en vigueur en 2018. Les citoyens russes peuvent en bénéficier sans avoir cotisé. En effet, à partir du $1^{\text {er }}$ janvier 2018, les familles russes qui ont leur premier enfant ont droit à cette allocation. Le montant et les conditions à remplir sont les mêmes que celles établies pour obtenir le versement mensuel du capital maternel. En cas de naissance (ou adoption) simultanée de deux enfants, la famille a la possibilité d'obtenir deux nouvelles allocations - l'une, financée directement par le budget, et l'autre, par le biais d'utilisation du capital maternel.

Par exemple, à Moscou, où le minimum vital de la population active pour le deuxième trimestre de l'année 2017 est de 18742 roubles (environ 272 euros) ${ }^{11}$, une famille avec trois enfants (un nouveau-né inclus) sera en mesure de percevoir un versement si son revenu total n'excède pas 84339 roubles (environ 1222 euros). Le montant de l'allocation mensuelle sera de 14252 roubles (environ 207 euros), le minimum vital des enfants. La même famille, qui habite à Saint Pétersbourg, peut obtenir 10367,90 roubles (environ 150 euros) si le revenu de la famille ne franchit pas la limite de 53 236,35 roubles (environ 772 euros), puisque le minimum vital de la population active dans cette ville est 11830,30 roubles (environ 171 euros) ${ }^{12}$.

10 Федеральный закон от 28.12.2017 n418-Ф3 «О ежемесячных выплатах семьям, имеющим Аетей » http://publication.pravo.gov.ru/Document/View/0001201712280088

11 Постановление Правительства Москвы от 12.09.2017 n 663-ПП «Об установлении величины прожиточного минимума в городе Москве за II квартал 2017 г. ». https://www.mos.ru/authority/documents/doc/36932220/

12 Постановление Правительства г. Санкт-Петербурга от 17.08 .2017 n693 «О6 установлении величины прожиточного минимума на душу населения и для основных социальноАемографических групп населения в Санкт-Петербурге за II квартал 2017 года ».

https://npa.gov.spb.ru/SpbGovSearch/Document/16789.html 
Sachant qu'en janvier 2018, selon les données officielles des statistiques, le taux de chômage des jeunes de moins de 25 ans a atteint $20,1 \%{ }^{13}$, et que le montant des indemnités de chômage n'a pas été modifié depuis 2008, son maximum étant de 4900 roubles (environ 71 euros), il est évident que la nouvelle allocation sera un soutien financier important, surtout pour les jeunes parents.

Il convient, par ailleurs de noter, que cette aide peut être cumulée avec les allocations de la sécurité sociale, dont, l'« allocation de grossesse et d'accouchement » (« пособие по беременности и родам »), la prime de naissance, l'indemnité mensuelle de congé parental. Leur montant respectif a été légèrement augmenté (multiplié par 1,025 fois) à partir de $1^{\text {er }}$ février $2018^{14}$. Certaines prestations ont un caractère plutôt symbolique, notamment, la prestation de 632,76 roubles (environ 9 euros) versée aux femmes qui ont déclaré leur grossesse avant la fin de la $12^{\mathrm{ème}}$ semaine de grossesse.

\section{III - LES PENSIONS}

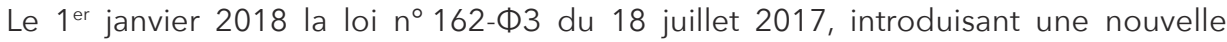
pension, est entrée en vigueur. Elle est destinée aux enfants de parents inconnus, c'est-àdire, aux enfants abandonnés dans les hôpitaux ou trouvés dans la rue. Ces enfants, selon la législation russe, n'ont pas de parents mentionnés dans leur certificat de naissance. En ce qui concerne les enfants nés en Crimée de parents inconnus avant mars 2014, selon la législation ukrainienne, les informations mentionnant les parents sont fausses. Les auteurs du projet de loi ont pris en compte ce fait en élaborant un texte de loi donnant le droit à tous les enfants russes quel que soit leur lieu de naissance de bénéficier de la nouvelle pension.

Les enfants de parents inconnus ont droit à la «pension sociale » à partir du jour de délivrance de leur certificat de naissance jusqu'à l'âge de 18 ans ou jusqu'à la fin de leur formation professionnelle suivie à temps plein dans des établissements d'enseignement. En toute hypothèse, le versement de la pension est suspendu lors du $23^{\text {ème }}$ anniversaire. S'il est adopté, l'enfant perd le bénéfice de sa pension. Le montant mensuel de la pension fixé par la loi est de 10 068,53 roubles (environ 146 euros). Elle est financée par le budget fédéral mais versée par le Fond de pension.

Cette nouvelle prestation a mis fin à l'inégalité entre les enfants nés de parents inconnus et les orphelins, qui en bénéficiaient depuis 1956. Selon les données officielles, le nombre d'enfants nés de parents inconnus en Russie est faible. En avril 2016, ils n'étaient que $880^{15}$, ce qui fait que cette nouvelle disposition n'aura pas un impact important sur le budget de l'État russe.

13 Les informations sur l'emploi et le chômage en Russie en janvier 2018 sont disponibles sur le site de l'agence des statistiques Rosstat http://www.gks.ru/wps/wcm/connect/rosstat main/rosstat/ru/statistics/wages/labour force/

14 Постановление Правительства РФ от 26.01.2018 n74 «Об утверждении коэффициента выплат, пособий и компенсаций в 2018 году». http://publication.pravo.gov.ru/Document/View/0001201801300027

15 La lettre explicative au projet de loi fédérale $n^{\circ}$ 22435-7. http://www.duma.khv.ru/Monitoring5/\%D 1\%84\%D0\%B0\%D0\%B9\%D0\%BB/1732394/8430 5-1-4-pdf 